\title{
Onset of clinical and MRI efficacy of ocrelizumab in relapsing multiple sclerosis
}

Frederik Barkhof, MD, Ludwig Kappos, MD, Jerry S. Wolinsky, MD, David K.B. Li, MD, Amit Bar-Or, MD, Hans-Peter Hartung, MD, Shibeshih Belachew, MD, PhD, Jian Han, PhD, Laura Julian, PhD,

Annette Sauter, PhD, Julie Napieralski, PhD, Harold Koendgen, MD, PhD, and Stephen L. Hauser, MD

Neurology ${ }^{\circledR}$ 2019;93:e1778-e1786. doi:10.1212/WNL.0000000000008189

\section{Abstract}

\section{Objective}

To assess the onset of ocrelizumab efficacy on brain MRI measures of disease activity in the phase II study in relapsing-remitting multiple sclerosis (RRMS), and relapse rate in the pooled phase III studies in relapsing multiple sclerosis (RMS).

\section{Methods}

Brain MRI activity was determined in the phase II trial at monthly intervals in patients with RRMS receiving placebo, ocrelizumab $(600 \mathrm{mg})$, or intramuscular interferon (IFN) $\beta$ - $1 \mathrm{a}$ $(30 \mu \mathrm{g})$. Annualized relapse rate (ARR; over various epochs) and time to first relapse were analyzed in the pooled population of the phase III OPERA (A Study of Ocrelizumab in Comparison With Interferon Beta-1a [Rebif] in Participants With Relapsing Multiple Sclerosis) I and OPERA II trials in patients with RMS receiving ocrelizumab (600 mg) or subcutaneous IFN- $\beta$-1a $(44 \mu \mathrm{g})$.

\section{Results}

In patients with RRMS, ocrelizumab reduced the number of new T1 gadolinium-enhancing lesions by week 4 vs placebo $(p=0.042)$ and by week 8 vs intramuscular IFN- $\beta$-1a $(p<0.001)$. Ocrelizumab also reduced the number of new or enlarging T2 lesions appearing between weeks 4 and 8 vs both placebo and IFN- $\beta$-1a (both $p<0.001$ ). In patients with RMS, ocrelizumab significantly reduced ARR $(p=0.005)$ and the probability of time to first protocol-defined relapse $(p=0.014)$ vs subcutaneous IFN- $\beta$-1a within the first 8 weeks.

\section{Conclusion}

Epoch analysis of MRI-measured lesion activity in the phase II study and relapse rate in the phase III studies consistently revealed a rapid suppression of acute MRI and clinical disease activity following treatment initiation with ocrelizumab in patients with RRMS and RMS, respectively.

\section{Classification of evidence}

This study provides Class II evidence that for patients with RRMS and RMS, ocrelizumab suppressed MRI activity within 4 weeks and clinical disease activity within 8 weeks.

\author{
Correspondence \\ Prof. Barkhof \\ f.barkhof@vumc.nl
}

\section{MORE ONLINE}

$\rightarrow$ Class of Evidence
Criteria for rating
therapeutic and diagnostic
studies
NPub.org/coe

$\rightarrow$ Class of Evidence Criteria for rating therapeutic and diagnostic studies

NPub.org/coe 


\section{Glossary}

ARR = annualized relapse rate; $\mathbf{B B B}=$ blood-brain barrier; $\mathbf{C I}=$ confidence interval; $\mathbf{D M T}=$ disease-modifying treatment; EDSS = Expanded Disability Status Scale; FS = Functional System; Gd = gadolinium; HR = hazard ratio; IFN = interferon; ITT = intent to treat; MS = multiple sclerosis; OPERA = A Study of Ocrelizumab in Comparison with Interferon Beta-1a [Rebif] in Participants with Relapsing Multiple Sclerosis; RMS = relapsing multiple sclerosis; ROW = rest of world; RRMS = relapsing-remitting multiple sclerosis.

In multiple sclerosis (MS), a rapid onset of action in controlling clinical and MRI disease activity is an important therapeutic goal to minimize neurologic damage and irreversible accumulation of disability. ${ }^{1-3}$ Pivotal studies of disease-modifying treatments (DMTs) in patients with relapsing-remitting MS (RRMS) have generally shown reductions in the annualized relapse rate (ARR) vs placebo or active comparator treatment over 1-2 years, ${ }^{4-19}$ although more recent studies, including post hoc analyses, have demonstrated benefits as early as 12 weeks after DMT initiation. ${ }^{1-3}$ However, the trial design and frequency of assessments often limit the study of onset of action, which particularly applies to MRI outcomes. ${ }^{2,20-22}$ In the 2 identical phase III trials, OPERA (A Study of Ocrelizumab in Comparison With Interferon Beta-1a [Rebif] in Participants With Relapsing Multiple Sclerosis) I and OPERA II, in patients with relapsing MS (RMS), ocrelizumab reduced ARR assessed at 96 weeks (primary outcome), compared with interferon (IFN) $\beta-$ 1a. In addition, reductions in MRI disease activity were observed as early as week 24 , commensurate with the first MRI assessment. ${ }^{23}$ In the phase II clinical trial of ocrelizumab in patients with RRMS, where MRI assessments were scheduled every 4 weeks for the first 6 months, reductions in MRI lesion measures were evident between 12 and 24 weeks. ${ }^{24}$

A rapid onset of ocrelizumab effect was observed on B-cell numbers, with near-complete depletion of $B$ cells in the peripheral blood by day 4 , although potentially this could occur within hours. ${ }^{25}$ The objective of the current study was to reanalyze ARR data from the pooled phase III OPERA I and OPERA II studies and MRI data from the phase II study at earlier time points than reported thus far.

\section{Methods}

\section{Trial design and patients}

New focal brain MRI activity (new T1 gadolinium [Gd]-enhancing lesions and new or enlarging T2 lesions) was determined in the phase II study (NCT00676715). This was a multicenter, randomized, parallel-group, partially blinded, placebo and IM IFN- $\beta$ - 1 a-controlled dosefinding study of ocrelizumab in patients with RRMS. Baseline demographics and disease characteristics were balanced across study arms. Study details have been reported previously (figure e-1, doi.org/10.5061/dryad.3jd86nj). ${ }^{24}$ Key eligibility criteria included age $18-55$ years, diagnosis of RRMS (2005 revised McDonald criteria), ${ }^{26}$ and an Expanded Disability Status Scale (EDSS) score of 1-6 at baseline. Patients were randomized (1:1:1:1) to receive placebo or low-dose $(600 \mathrm{mg})$ or high-dose $(2,000 \mathrm{mg})$ ocrelizumab in 2 doses on days 1 and 15 , or IM IFN- $\beta$-1a $(30 \mu \mathrm{g})$ once a week (figure e-1, doi.org/10. 5061/dryad.3jd86nj), with 4-weekly MRI scans performed for the first 6 months. ${ }^{24}$ In this study, analysis of brain MRI activity was conducted using the intent-to-treat (ITT) population, only in patients receiving $600 \mathrm{mg}$ ocrelizumab (the current approved dose), to be comparable with the phase III trials in RMS.

ARR was determined in the pooled population of the identical phase III, multicenter, randomized, double-blind, doubledummy, SC IFN- $\beta$-1a-controlled trials of ocrelizumab in patients with RMS (OPERA I [NCT01247324] and OPERA II [NCT01412333]). ${ }^{23}$ Baseline demographics and disease characteristics were comparable across treatment arms within each study, and between studies. Study details have been reported previously (figure e-2, doi.org/10.5061/dryad. 3 jd86nj). ${ }^{23}$ Key eligibility criteria included age $18-55$ years, diagnosis of relapsing MS (2010 revised McDonald criteria), ${ }^{27}$ and an EDSS score of 0-5.5 at screening. Consistency of baseline characteristics and treatment effects across both OPERA studies met predetermined criteria for pooled efficacy analysis, including ARR. ${ }^{23}$ Patients were randomized (1: 1) to receive either $600 \mathrm{mg}$ ocrelizumab by IV infusion every 24 weeks or SC IFN- $\beta$-1a 3 times per week at a dose of $44 \mu \mathrm{g}$ throughout the 96-week treatment period. Relapse information was collected continuously through scheduled neurologic examinations, and any unscheduled visit triggered by the patient or through structured telephone interviews conducted every 4 weeks from week 8 to identify any new or worsening neurologic symptoms (figure e-2, doi.org/10. 5061/dryad.3jd86nj). ${ }^{23}$

\section{Standard protocol approvals, registrations, and patient consents}

The relevant institutional review boards/ethics committees approved the protocols (ClinicalTrials.gov identifier numbers NCT00676715, NCT01247324, and NCT01412333). All patients provided written informed consent.

\section{Classification of evidence}

This study provides Class II evidence that for patients with RRMS and RMS, ocrelizumab suppressed MRI activity within 4 weeks and clinical disease activity within 8 weeks.

\section{Laboratory assessments}

CD19 count is a sensitive but nonspecific pharmacodynamic marker for anti-CD20 efficacy. In the OPERA I and OPERA II 
trials, anti-CD19 was used to measure CD20-positive cells as ocrelizumab would interfere with an anti-CD20 assay.

\section{Clinical and MRI endpoints}

The primary endpoint of the OPERA I and OPERA II trials was ARR at 96 weeks, which reflects the number of relapses meeting the prespecified criteria observed per person-year of follow-up. The probability of first protocol-defined relapse was also determined. Protocol-defined relapses were defined as new or worsening neurologic symptoms attributable to MS that persisted for over 24 hours, were immediately preceded by a stable or improving neurologic state for at least 30 days, and were accompanied by objective neurologic worsening consistent with an increase of at least half a step on the EDSS scale, 2 points on at least one of the appropriate Functional System (FS) scale scores, or one point on 2 or more FS scale scores. ${ }^{23}$ In the phase II study, brain MRI was performed at baseline and weeks $4,8,12,16,20$, and 24 during the core placebocontrolled period and at the end of the dose-blinded extension at week 96 in the ocrelizumab arm only; new T1 Gd-enhancing lesions or new or enlarging $\mathrm{T} 2$ lesions on any postbaseline scan were considered evidence of MRI disease activity.

\section{Statistical analyses}

In the ITT population in the phase II study, acute MRI disease activity data were reanalyzed up to week 12 by 4-weekly epochs. The number of new T1 Gd-enhancing lesions (at weeks 4,8 , and 12) and the number of new or enlarging T2 lesions, regardless of enhancement status (during weeks 0-4, $4-8$, and 8-12), were compared in patients treated with $600 \mathrm{mg}$ ocrelizumab and those receiving placebo or IM IFN$\beta$-1a using a negative binomial model adjusted for baseline lesion status (present vs absent in T1 Gd-enhancing lesions for T1 model; total T2 lesion volume for T2 model), baseline EDSS score $(\leq 2.5 \mathrm{vs}>2.5)$, and geographic region (US vs rest of world $[\mathrm{ROW}]$ ). The phase II MRI data were originally analyzed using the van Elteren test, stratified by geographic region and presence of baseline Gd-enhancing lesions (absent or present $)^{24}$; however, the negative binomial model was adopted here, consistent with the MRI analyses in the phase III OPERA I and OPERA II studies. ${ }^{23}$ The negative binomial model was adjusted for baseline EDSS score and geographic region as there is an underlying assumption that these predefined subgroups of patients may behave differently.

Based on the ITT population over the controlled treatment phase (baseline to 96 weeks) from the pooled OPERA I and OPERA II data, post hoc exploratory analyses evaluated the effect of ocrelizumab compared with SC IFN- $\beta$ - 1 a on ARR for several epochs, including weeks $0-8,0-12,0-24$, and $0-48$. For each epoch, the adjusted ARR, rate ratio (ocrelizumab over SC IFN- $\beta-1 \mathrm{a})$ and its $95 \%$ confidence interval (CI), and the $p$ value were derived from the Poisson model adjusting for study (OPERA I vs OPERA II), region (US vs ROW), and baseline EDSS score ( $<4.0 \mathrm{vs} \geq 4.0)$. The log-transformed exposure time in years was included as an offset variable for appropriate computation of relapse rate. The probability of time to first protocol-defined relapse at weeks 8, 16, 24, 48, 72, and 96 was estimated using the Kaplan-Meier method and Greenwood formula. The hazard ratios (HRs) (ocrelizumab vs SC IFN$\beta-1 \mathrm{a})$ and $95 \%$ CIs were based on a Cox proportional hazards model, adjusting for study (OPERA I vs OPERA II), region (US vs ROW), and baseline EDSS score $(<4.0$ vs $\geq 4.0)$. $p$ Values were not adjusted for multiple comparisons.

\section{Data availability}

Qualified researchers may request access to individual patientlevel data through the clinical study data request platform (clinicalstudydatarequest.com). Further details on Roche criteria for eligible studies are available here (clinicalstudydatarequest.com/Study-Sponsors/Study-Sponsors-Roche.aspx). For further details on the Roche Global Policy on the Sharing of Clinical Information and how to request access to related clinical study documents, see roche.com/research_and_development/who_we_are_how_we_work/clinical_trials/our commitment_to_data_sharing.htm.

\section{Results}

\section{Patient demographics and disease characteristics}

In the phase II trial, the population analyzed included 163 patients treated with placebo, $\mathrm{n}=54 ; 30 \mu \mathrm{g}$ IM IFN- $\beta-1 \mathrm{a}, \mathrm{n}=$ 54; or $600 \mathrm{mg}$ ocrelizumab, $\mathrm{n}=55$ (the ocrelizumab high dose was not included in this analysis). In the OPERA I and OPERA II trials, the pooled population comprised 1,656 patients ( $44 \mu \mathrm{g}$ SC IFN- $\beta-1 \mathrm{a}, \mathrm{n}=829$; ocrelizumab, $\mathrm{n}=827$ ). Baseline demographics and disease characteristics were similar within each study arm and between studies for the phase II and pooled phase III patient populations, although mean EDSS was higher and there were fewer treatment-naive patients in the phase II study compared with the pooled phase III study population (table).

\section{Changes in B-cell numbers on ocrelizumab treatment initiation}

CD19+ cells represent a measure of B-cell counts in antiCD20-treated patients. In the pooled OPERA I and OPERA II population, the level of CD19+ cells decreased to negligible levels with ocrelizumab treatment by week 2 (figure e-3, doi. org/10.5061/dryad.3jd86nj).

\section{New focal brain MRI activity in the phase II study}

MRI lesion activity was determined in the phase II study up to week 12 by 4 -weekly epochs, comparing patients treated with ocrelizumab $600 \mathrm{mg}$ with those receiving placebo or IM IFN$\beta$-1a. In the primary analysis of the phase II study, ocrelizumab $600 \mathrm{mg}$ reduced the cumulative number of T1 Gd-enhancing lesions observed between weeks 12 and 24 by $89 \%$ (95\% CI $68 \%-97 \%)$ compared with placebo $(p<0.001){ }^{24}$ The total number of new or enlarging T2 lesions at week 24 was reduced with ocrelizumab $600 \mathrm{mg}$ (mean [SD] 0.0 [0.1]) compared with placebo $(p<0.001){ }^{24}$ By performing an 
Table Baseline demographics and disease characteristics for phase II and pooled OPERA I and OPERA II populations

\begin{tabular}{|c|c|c|c|c|c|}
\hline \multirow[b]{2}{*}{$\begin{array}{l}\text { Baseline demographics and } \\
\text { disease characteristics }\end{array}$} & \multicolumn{3}{|l|}{ Phase II } & \multicolumn{2}{|c|}{ Pooled OPERA I and OPERA II } \\
\hline & $\begin{array}{l}\text { Placebo } \\
(n=54)\end{array}$ & $\begin{array}{l}\text { IM IFN- } \beta-1 a \\
30 \mu g(n=54)\end{array}$ & $\begin{array}{l}\text { Ocrelizumab, } \\
600 \mathrm{mg}(\mathrm{n}=55)\end{array}$ & $\begin{array}{l}\text { SC IFN- } \beta-1 a \text {, } \\
44 \mu g(n=829)\end{array}$ & $\begin{array}{l}\text { Ocrelizumab, } \\
600 \mathrm{mg}(n=827)\end{array}$ \\
\hline Age, $y$, mean (SD) & $38.0(8.8)$ & $38.1(9.3)$ & $35.6(8.5)$ & $37.2(9.2)$ & $37.1(9.2)$ \\
\hline Female, n (\%) & $36(66.7)$ & $32(59.3)$ & $35(63.6)$ & $552(66.6)$ & $541(65.4)$ \\
\hline \multicolumn{6}{|l|}{ Time since MS symptom onset, y } \\
\hline Mean (SD) & $7.2(6.1)$ & $8.4(7.2)$ & $6.9(5.0)$ & $6.5(6.1)$ & $6.7(6.2)$ \\
\hline Median (range) & $4.8(0.6-26.2)$ & $5.3(0.8-35.2)$ & $6.5(0.5-20.5)$ & $4.8(0.2-34.9)$ & $5.1(0.2-33.9)$ \\
\hline \multicolumn{6}{|l|}{ Time since MS diagnosis, y } \\
\hline Mean (SD) & $3.9(4.6)$ & $5.1(5.2)$ & $4.7(4.1)$ & $3.9(4.9)$ & $4.0(4.9)$ \\
\hline Median (range) & $2.7(0.1-19.2)$ & $3.3(0.1-20.2)$ & $3.6(0.1-16.5)$ & $1.7(0.1-28.5)$ & $1.8(0.0-28.9)$ \\
\hline MS disease-modifying treatment-naive, $\mathbf{n}(\%)^{a}$ & $38(70.4)$ & $31(57.4)$ & $30(54.5)$ & $606(73.4)^{b, c}$ & $605(73.3)^{b, d}$ \\
\hline \multicolumn{6}{|l|}{ EDSS } \\
\hline Mean (SD) & $3.2(1.4)$ & $3.1(1.5)$ & $3.5(1.5)$ & $2.8(1.3)^{\mathrm{e}}$ & $2.8(1.3)$ \\
\hline Median (range) & $3.0(1.0-6.0)$ & $3.0(1.0-6.0)$ & $3.5(1.0-6.0)$ & $2.5(0.0-6.0)^{\mathrm{e}}$ & $2.5(0.0-6.0)$ \\
\hline \multicolumn{6}{|l|}{ MRI } \\
\hline Patients with T1 Gd-enhancing lesions, n (\%) & $21(44.7)^{f}$ & $17(34.0)^{g}$ & $26(51.0)^{\mathrm{h}}$ & $327(39.8)^{i}$ & $333(40.7)^{j}$ \\
\hline \multicolumn{6}{|l|}{ Brain T2 hyperintense lesion volume, $\mathrm{cm}^{3}$} \\
\hline Mean (SD) & $9.0(9.8)^{f}$ & $13.2(17.2)^{k}$ & $14.0(19.9)^{\mathrm{h}}$ & $10.2(11.8)^{\prime}$ & $10.8(14.1)^{i}$ \\
\hline Median (range) & $4.8(0.0-39.9)^{f}$ & $8.2(0.0-102.9)^{k}$ & $6.7(0.0-93.8)^{\mathrm{h}}$ & $6.2(0.0-76.1)^{1}$ & $5.4(0.0-96.0)^{i}$ \\
\hline \multicolumn{6}{|c|}{ 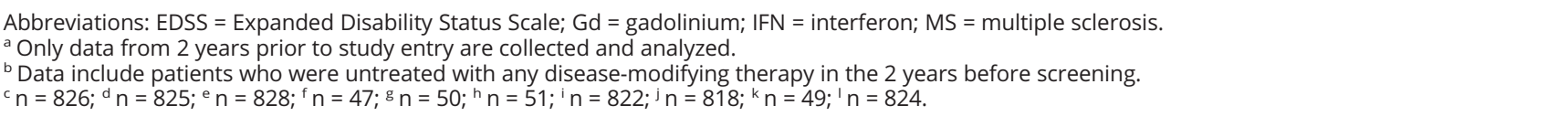 } \\
\hline
\end{tabular}

epoch analysis of lesion activity by 4-weekly intervals from baseline to week 12 , we found that ocrelizumab significantly reduced the number of new T1 Gd-enhancing lesions by week 4 vs placebo (adjusted mean: placebo 0.839 , ocrelizumab $600 \mathrm{mg} 0.319, p=0.042$ ) and by week 8 vs IM IFN- $\beta$-1a (adjusted mean: IM IFN- $\beta$-1a 1.276 , ocrelizumab $600 \mathrm{mg}$ 0.041, $p<0.001$ ) (figure 1). Ocrelizumab also significantly reduced the number of new or enlarging T2 lesions appearing between weeks 4 and 8 vs placebo (adjusted mean: placebo 1.205 , ocrelizumab $600 \mathrm{mg} 0.056, p<0.001)$ and IM IFN$\beta$-1a (adjusted mean: IM IFN- $\beta$-1a 0.968, ocrelizumab

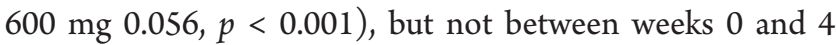
(figure 2). Furthermore, separately, the number of new T2 lesions (figure e-4, doi.org/10.5061/dryad.3jd86nj) and the number of newly enlarging T2 lesions (figure e-5, doi.org/10. 5061/dryad.3jd86nj) appearing between weeks 4 and 8 were significantly reduced with ocrelizumab vs placebo and IM IFN- $\beta-1$ a. In addition, the proportion of patients free of T1 Gd-enhancing lesions at each measured epoch from week 4 to week 12 in 4-weekly intervals was higher with ocrelizumab vs placebo and IM IFN- $\beta$-1a (figure 3). Analysis of MRI lesion measures to week 24 was also performed and results were consistent with week 12 (data not shown). Consistent results in brain MRI activity were also observed with ocrelizumab 2,000 $\mathrm{mg}$ (data not shown).

\section{Clinical activity in the phase III OPERA I and OPERA II studies}

In the pooled analyses of the OPERA I and OPERA II trials, ocrelizumab significantly reduced ARR, the primary outcome in the OPERA studies, by $46.5 \%(p<0.001)$ over 96 weeks compared with SC IFN- $\beta$-1a (figure 4). This favorable outcome on ARR was seen with ocrelizumab compared with SC IFN- $\beta$-1a, at the various epochs studied: ocrelizumab significantly reduced ARR within the first 8 weeks $(54.9 \%, p=0.005), 12$ weeks (48.8\%, $p=0.002)$, 24 weeks ( $40.4 \%, p<0.001)$, and 48 weeks $(48.7 \%, p<0.001)$ (figure 4). ARR was consistent for treatmentnaive patients, as per the OPERA definition, and DMT switchers. However, this is a small cohort only, mostly consisting of patients previously treated with IFN and glatiramer acetate, therefore underpowered to detect differences between groups.

In addition, analysis of time to first onset of protocol-defined relapse demonstrated a lower relative risk of experiencing a relapse with ocrelizumab by week 8 (SC IFN- $\beta$-1a 0.04 [95\% CI 0.03-0.05], ocrelizumab 0.02 [95\% CI 0.01-0.03], $p=$ 


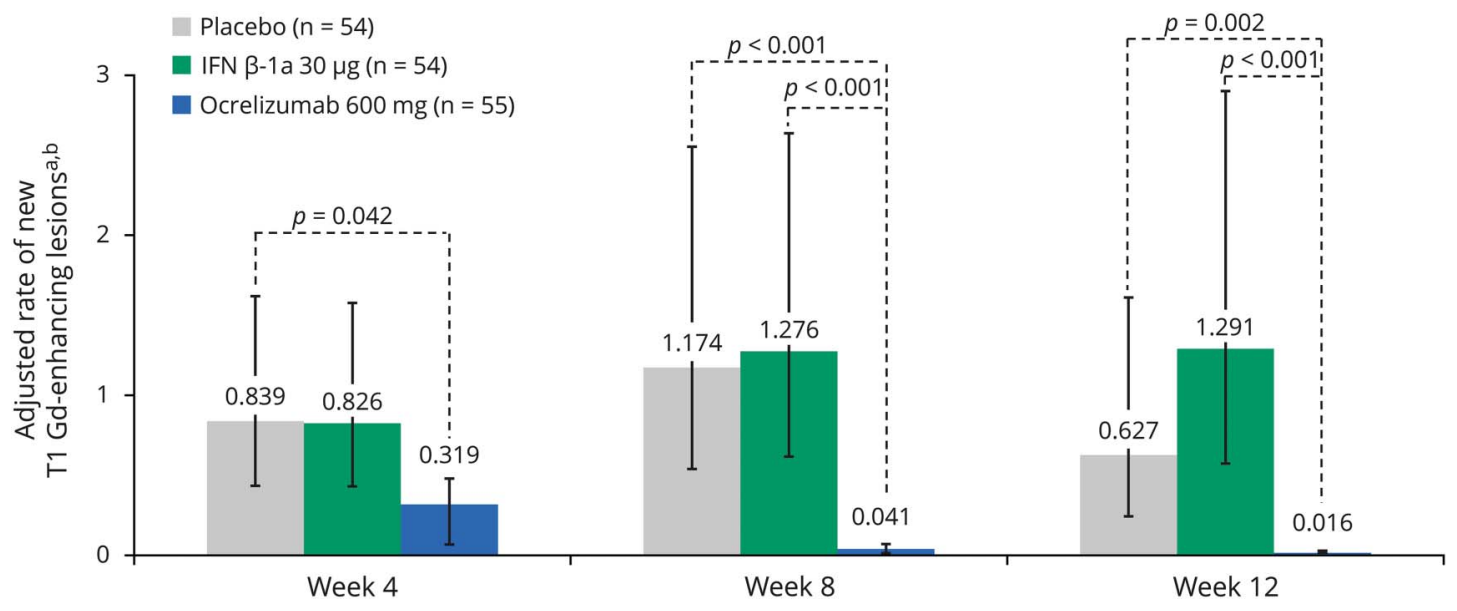

Intention-to-treat population. Interferon (IFN)- $\beta$-1 a was administered as a $30 \mu \mathrm{g}$ IM injection once a week. ${ }^{2}$ Negative binomial model adjusted for baseline T1 Gd-enhancing lesions (present vs absent), baseline Expanded Disability Status Scale (EDSS) score ( $\leq 2.5$ vs $>2.5$ ), and geographic region (US vs rest of world). ${ }^{\mathrm{b}}$ Error bars are $95 \%$ confidence intervals.

0.014) (figure 5), and over all subsequent intervals (week 16, $24,48,72$, and 96 ; all $p<0.002$ ). The cumulative probability of first protocol-defined relapse at 96 weeks was $0.32(95 \% \mathrm{CI}$ $0.28-0.35$ ) for SC IFN- $\beta$-1a and 0.19 (95\% CI 0.16-0.21) for ocrelizumab $(p<0.001)$ (figure 5). Treatment with ocrelizumab led to a $46 \%$ risk reduction in time to first protocoldefined relapse over 96 weeks compared with SC IFN- $\beta$-1a (HR 0.54 [95\% CI 0.44-0.66], $p<0.001$ ).

\section{Discussion}

This post hoc analysis of phase II and pooled phase III studies demonstrated that ocrelizumab has a rapid onset of activity as early as 4 weeks. Epoch analysis of MRI-measured new focal lesion activity in the phase II study and relapse rate in the phase III studies consistently disclosed a rapid suppression of acute MRI and clinical disease activity following treatment initiation, respectively. In the 2 OPERA studies in patients with RMS, ocrelizumab was associated with a significant reduction in relapse rate and the cumulative probability of first protocol-defined relapse over time, as early as 8 weeks after treatment initiation, suggesting a rapid onset of clinical efficacy. The rapid onset of the effect of ocrelizumab on acute clinical disease activity in the phase III trials corresponds temporally with the observed effect on acute new focal MRI disease activity in the phase II analysis. Ocrelizumab $600 \mathrm{mg}$ demonstrated rapid suppression of new focal brain MRI activity vs placebo as early as week 4 , and near-complete by week

Figure 2 The number of new or enlarging $T 2$ lesions in the phase II population

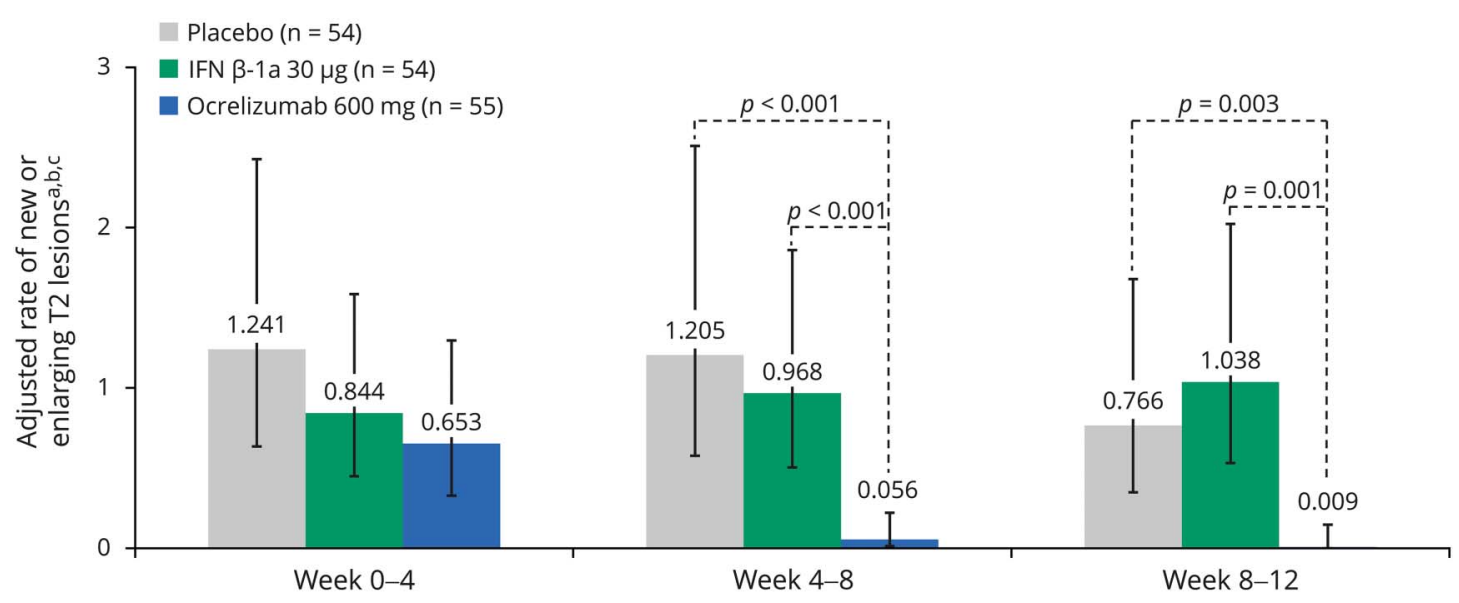

Intention-to-treat population. Interferon (IFN)- $\beta$-1a was administered as a $30 \mu \mathrm{g}$ IM injection once a week. ${ }^{\mathrm{a}}$ Enlarging T2 lesions were newly enlarging. ${ }^{b}$ Negative binomial model adjusted for baseline T2 lesion volume, baseline Expanded Disability Status Scale (EDSS) Score ( $\leq 2.5$ vs $>2.5$ ), and geographic region (US vs rest of world). 'Error bars are 95\% confidence intervals. 


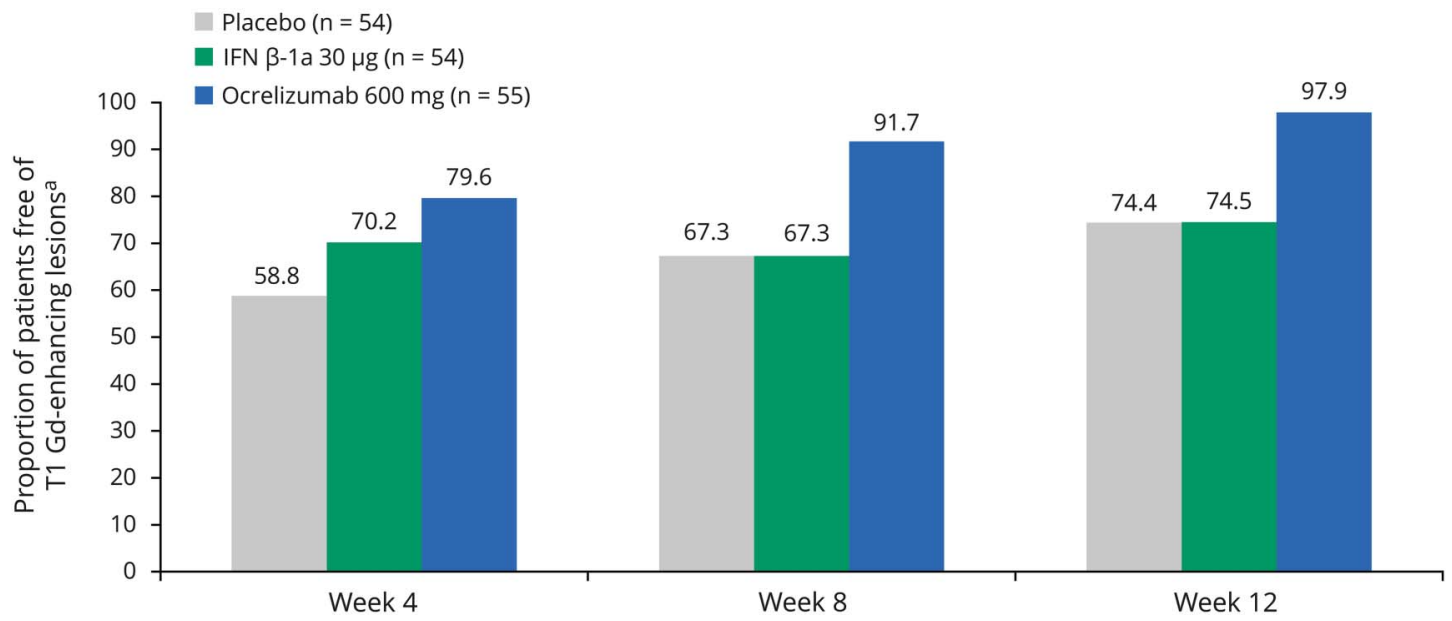

Intention-to-treat population. Interferon (IFN)- $\beta-1$ a was administered as a $30 \mu \mathrm{g} I \mathrm{M}$ injection once a week. Proportion of patients free of T1 Gd-enhancing lesions at week 24: placebo 74.5\%; IFN- $\beta-1$ a $30 \mu \mathrm{g} 61.4 \%$; ocrelizumab $600 \mathrm{mg} \mathrm{100 \% .}{ }^{a}$ For the calculation of total number of new Gd-enhancing T1 lesions on MRI scans of the brain at a specific week and before week 24 , the missing value at a time point is not going to be imputed.

8. Post hoc analyses of clinical study data have shown reductions in ARR within the first 12 weeks vs placebo for natalizumab, fingolimod, and dimethyl fumarate. ${ }^{1-3}$ Conversely, the early benefits on MRI measures after DMT initiation seen at 1, 3, and 6 months for natalizumab, dimethyl fumarate, and fingolimod vs placebo were dependent on the first available MRI scheduled assessments. ${ }^{2,20-22}$ Similarly, in the ocrelizumab pivotal studies in RMS, most of the new or enlarging $\mathrm{T} 2$ lesions in the ocrelizumab groups occurred between baseline and week 24 (first scheduled scan), perhaps reflecting residual new T2 lesion formation carried over within the first weeks of treatment initiation, ${ }^{28}$ and nearcomplete suppression of T1 Gd-enhancing lesions at week 24.
The current analysis of phase II MRI data of the ocrelizumab $600 \mathrm{mg}$ dose, with increased scan frequency, reveals the suppression of new focal brain MRI lesion activity was in fact near-complete by week 8 . As early treatment initiation can minimize neurologic damage and disability worsening in patients with MS, and is associated with improved clinical outcomes, the available data from this study and the pivotal trials suggest ocrelizumab could provide both early and longterm benefits in patients with MS.

The fast B-cell depletion in the peripheral blood may, in part, explain the rapid efficacy of ocrelizumab. These findings are consistent with previous observations and the known

Figure 4 The adjusted annualized relapse rate (ARR) in the pooled OPERA intention-to-treat (ITT) population

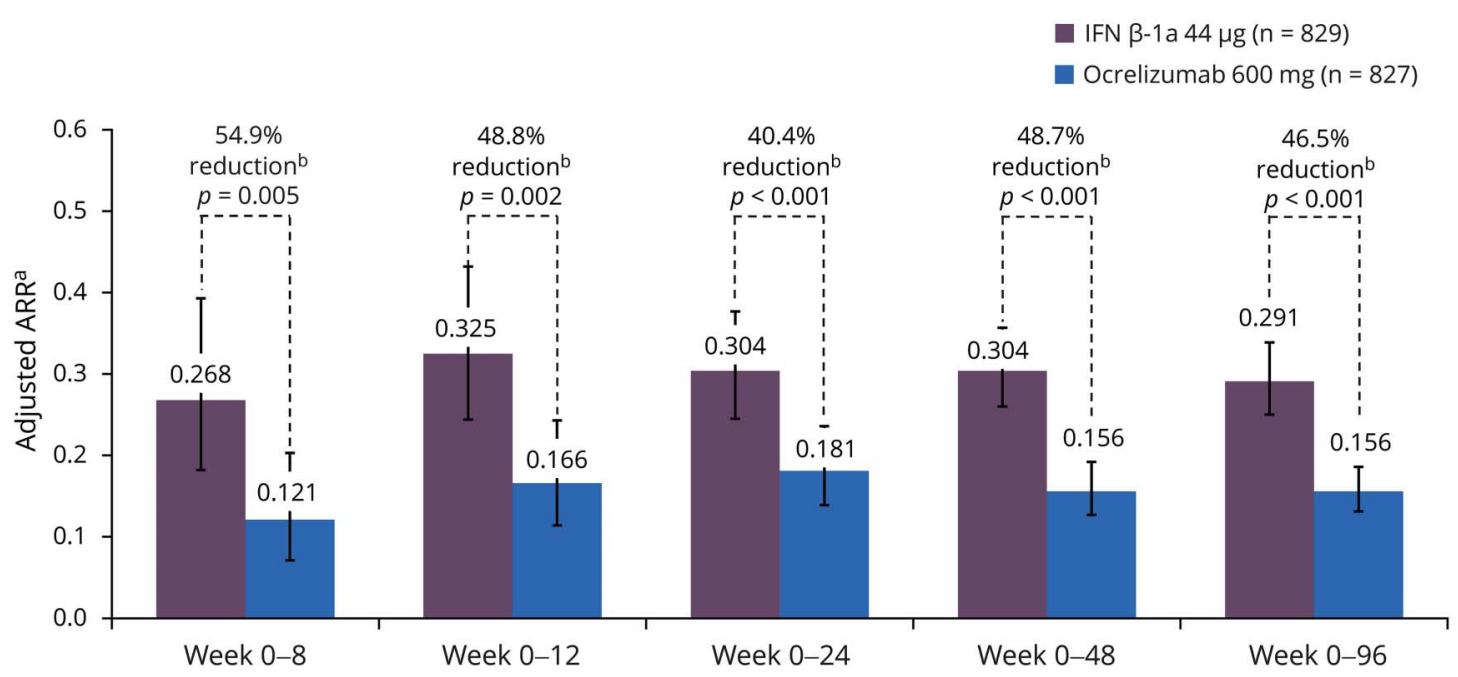

Intention-to-treat population. Interferon (IFN)- $\beta$-1a was administered as an SC infusion 3 times per week at a dose of 44 $\mu$ g. ${ }^{a}$ Adjusted by study, baseline Expanded Disability Status Scale (EDSS) score (<4.0 vs $\geq 4.0$ ), and geographic region (US vs rest of world) using Poisson model. ${ }^{\text {b }}$ Compared with IFN- $\beta-1$ a. 


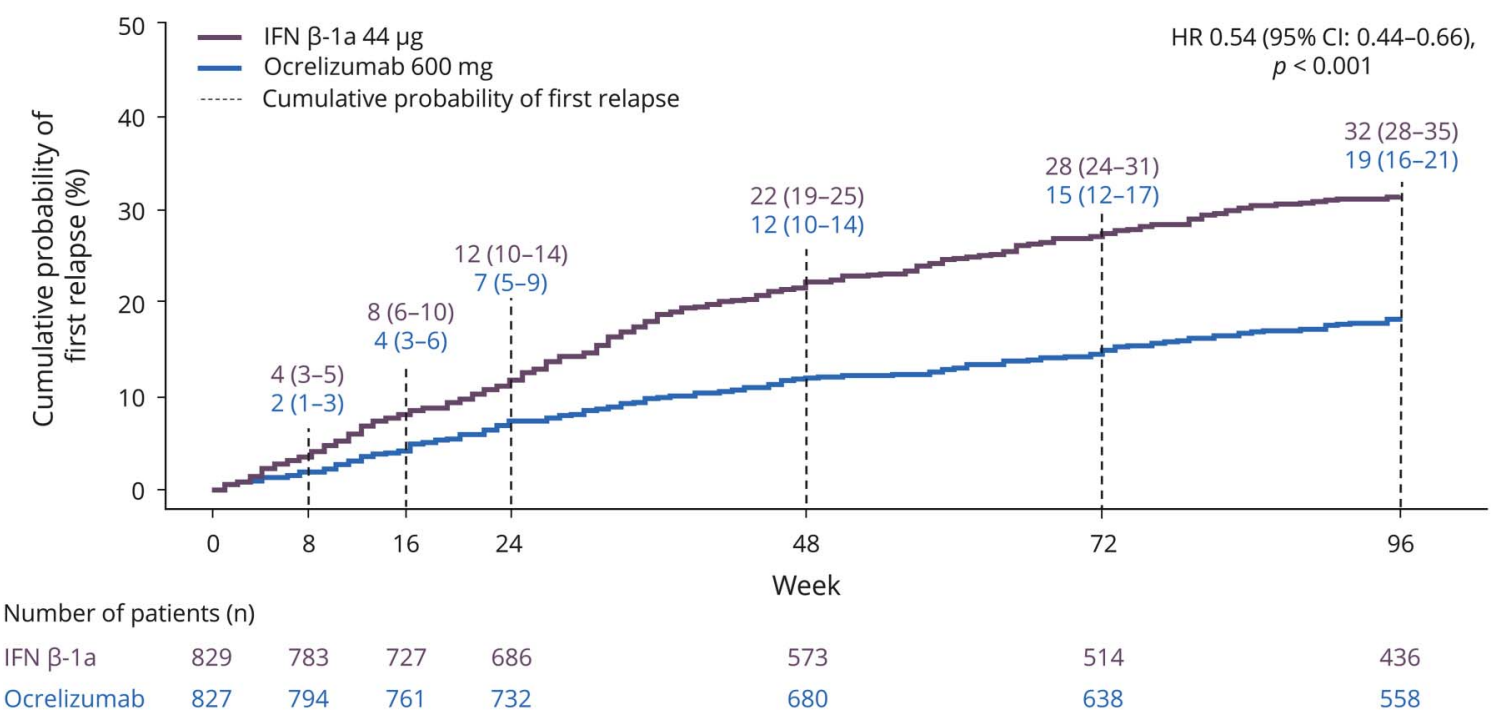

Intention-to-treat population. Interferon (IFN)- $\beta$-1 a was administered as an SC infusion 3 times per week at a dose of $44 \mu \mathrm{g}$. Probability of relapse estimates (95\% confidence interval $[\mathrm{Cl}]$ ) at weeks $8,16,24,48,72$, and 96 were calculated using Kaplan-Meier and Greenwood formula. $p$ Values not adjusted for multiplicity of testing. $\mathrm{HR}=$ hazard ratio.

pharmacodynamic effects of ocrelizumab, which were associated with systemic depletion of B cells to negligible levels within 4 days (first available assessment in humans) or potentially earlier. ${ }^{25,29}$ This may in turn lead to downregulation of circulating $\mathrm{T}$ cells and their entrance into the CNS. ${ }^{30}$ The explanation of the rapid onset of efficacy on T1 Gd-enhancing lesions with ocrelizumab will require a better understanding of the contributing factors to the integrity of the blood-brain barrier (BBB) and what role B cells and their depletion play in the interaction with $\mathrm{T}$ cells and possibly myeloid/glial cells. Initial studies in a limited number of patients with MS suggest that anti-CD20 therapies (rituximab and ocrelizumab) modulate (B-cell-derived) circulating cytokine levels, which may influence $B B B$ permeability.

Limitations exist in the data presented. As the analyses were post hoc, no adjustment for multiplicity was made; however, all results are in the same direction and reveal, as expected, a further increasing treatment effect over time. It should be noted that the $p$ values reported should be interpreted with a certain degree of caution. Despite most baseline demographics and disease characteristics being similar between studies for the phase II and pooled OPERA I and OPERA II patient populations, there were some differences between these 2 populations for EDSS and MS disease-modifying treatment-naive participants. In addition, the populations were different between the phase II study (patients with RRMS) and the pooled OPERA I and OPERA II studies (patients with RMS). With this and other clinical studies, the assessment time points defined in the study protocol limit the study of the onset of a measurable treatment effect on outcomes (here B-cell depletion, MRI activity, and clinical activity). The rapid onset of action of ocrelizumab was assessed using an active drug (SC IFN- $\beta$-1a), which should be considered when comparing the time to effect with other DMTs in studies which were placebo controlled. ${ }^{1-3}$ Although the treating physician does not conduct the assessment for ARR, IFN- $\beta$-1a flu-like side effects can potentially unblind patients and affect their initiation of relapse evaluation.

Although benefit/risk was not analyzed in DMT switchers in this study, the rapid onset of the ocrelizumab effect may have implications for patients switching from other therapies. Patients and clinicians are concerned that delayed onset of therapeutic effect, either with new treatments or after switching, can put patients at risk of new relapses and lead to an increase in disability. Treatment onset of ocrelizumab on ARR was found to be consistent with treatment-naive patients for IFN and glatiramer acetate switchers; numbers for patients switching from other DMTs were too low for meaningful analyses. Rapid control of subclinical disease activity is an important treatment goal to minimize disease activity and potentially associated axonal damage that may ultimately lead to disability progression in MS. ${ }^{31}$ This should be balanced against potential safety concerns when switching between drugs that may have additive pharmacodynamic effects. Patients with RRMS with a suboptimal response to previous DMTs switching to ocrelizumab are being studied in 2 ongoing phase IIIb MS trials (CHORDS [NCT02637856] and CASTING [NCT02861014]).

Overall, ocrelizumab consistently demonstrated a rapid onset of efficacy on both clinical and MRI measures of acute disease activity, as early as 4 weeks, in the phase II and pooled phase III OPERA I and OPERA II trials. Future analyses, including post hoc exploratory analyses using data from the open-label 
extension study, should help to identify if patients who switch from IFN- $\beta$ - 1 a to ocrelizumab demonstrate a similar rapid suppression of clinical and MRI disease activity, and whether the early effects of ocrelizumab translate into long-term benefit in patients continuing ocrelizumab treatment.

\section{Acknowledgment}

The authors thank the patients, their families, the UBC MS/ MRI Research Group, and the investigators who participated in this trial. Qualified researchers may request access to individual patient-level data through the clinical study data request platform (clinicalstudydatarequest.com). Further details on Roche criteria for eligible studies are available at clinicalstudydatarequest.com/Study-Sponsors/Study-Sponsors-Roche.aspx. For further details on the Roche Global Policy on the Sharing of Clinical Information and how to request access to related clinical study documents, see roche. com/research_and_development/who_we_are_how_we_ work/clinical_trials/our_commitment_to_data_sharing.htm.

\section{Study funding}

This research was funded by F. Hoffmann-La Roche Ltd, Basel, Switzerland. Heather Latimer of Articulate Science, UK, wrote the first draft of the manuscript based on input from the authors, which was funded by F. Hoffmann-La Roche Ltd. The authors had full editorial control of the manuscript and provided their final approval of all content.

\section{Disclosure}

F. Barkhof is an editorial board member for the publications Brain, European Radiology, Multiple Sclerosis Journal, Neurology ${ }^{\circledR}$, and Radiology; has received consultancy fees from Bayer Schering, Biogen Idec, F. Hoffmann-La Roche Ltd., Genzyme, Janssen Research, Merck Serono, Novartis, Synthon, and Teva; has received grants from the Dutch MS Society (EU-FP7/ Horizon 2020); has received payments for developing educational presentations, including service on speakers bureaus, for Biogen and IXICO; and is supported by the NIHR UCLH Biomedical Research Centre. L. Kappos' institution (University Hospital Basel) received the following in the last 3 years, used exclusively for research support at the department: steering committee, advisory board, and consultancy fees from Actelion, Alkermes, Almirall, Bayer, Biogen, Celgene/Receptos, df-mp, Excemed, GeNeuro SA, Genzyme, Japan Tobacco, Merck, Minoryx, Mitsubishi Pharma, Novartis, Roche, Sanofi-Aventis, Santhera, Teva, and Vianex, and license fees for NeurostatusUHB products; the Research of the MS Center in Basel has been supported by grants from Bayer, Biogen, Novartis, the Swiss MS Society, the Swiss National Research Foundation, the European Union, and Roche Research Foundations. J. Wolinsky has received personal compensation for consulting, serving on a scientific advisory board, speaking, or other activities with AbbVie, Actelion, Alkermes, Biogen, Bionest, Celgene, Clene Nanomedicine, EMD Serono, Forward Pharma A/S, GeNeuro, MedDay Pharmaceuticals, Novartis, Otsuka, PTC Therapeutics, Roche/Genentech, and Sanofi Genzyme; royalties are received for out-licensed monoclonal antibodies through UTHealth from
Millipore Corporation. D.K.B. Li has received research funding from the Canadian Institutes of Health Research and Multiple Sclerosis Society of Canada; he is the director of the UBC MS/ MRI Research Group, which has been contracted to perform central analysis of MRI scans for therapeutic trials with Novartis, F. Hoffmann-La Roche Ltd., Perceptives, and Sanofi-Aventis; and the UBC MS/MRI Research Group has also received grant support for investigator-initiated independent studies from $\mathrm{F}$. Hoffmann-La Roche Ltd., Genzyme, Merck-Serono, and Novartis. D.K.B. Li has acted as a consultant for Vertex Pharmaceuticals and has served on the data and safety advisory board for Opexa Therapeutics and scientific advisory boards for Adelphi Group, F. Hoffmann-La Roche Ltd., and Novartis; he has also given lectures that have been supported by unrestricted education grants from Biogen and Novartis. A. Bar-Or has served on scientific advisory boards for Biogen, F. Hoffmann-La Roche Ltd., Genentech, Inc., GlaxoSmithKline, Guthy-Jackson/ GGF, MedImmune, Merck/EMD Serono, Mitsubishi Tanabe, Ono, Receptos, and Sanofi Genzyme; and has received research support from Novartis and Sanofi Genzyme. H.-P. Hartung has received honoraria for consulting, serving on steering committees, and speaking at scientific symposia with approval by the Rector of Heinrich Heine University from Bayer, Biogen, F. Hoffmann-La Roche Ltd., GeNeuro SA, Genzyme, MedImmune, Merck Serono, Novartis, Octapharma, Teva, and Sanofi. S. Belachew was an employee of F. Hoffmann-La Roche Ltd. during the completion of the work related to this manuscript. S. Belachew is now an employee of Biogen (Cambridge, MA), which was not in any way associated with this study. J. Han is an employee of Genentech, Inc. L. Julian is an employee of Genentech, Inc., and a shareholder of F. Hoffmann-La Roche Ltd. A. Sauter is an employee and shareholder of F. Hoffmann-La Roche Ltd. J. Napieralski is an employee of F. Hoffmann-La Roche Ltd. H. Koendgen is an employee and shareholder of $\mathrm{F}$. Hoffmann-La Roche Ltd. S. Hauser serves on the board of trustees for Neurona and on scientific advisory boards for Annexon, Bionure, and Symbiotix, and has received travel reimbursement and writing assistance from F. HoffmannLa Roche Ltd. for CD20-related meetings and presentations. Go to Neurology.org/N for full disclosures.

\section{Publication history}

Received by Neurology November 5, 2018. Accepted in final form May 30, 2019.

Appendix Authors

\begin{tabular}{|c|c|c|c|}
\hline Name & Location & Role & Contribution \\
\hline F. Barkhof & $\begin{array}{l}\text { VU University } \\
\text { Medical Centre, } \\
\text { Amsterdam, the } \\
\text { Netherlands } \\
\text { UCL Institutes of } \\
\text { Biomedical } \\
\text { Engineering and } \\
\text { Neurology, London, } \\
\text { UK }\end{array}$ & Author & $\begin{array}{l}\text { Designed and } \\
\text { conceptualized study, } \\
\text { reviewed the data, } \\
\text { drafted and revised the } \\
\text { manuscript content }\end{array}$ \\
\hline
\end{tabular}


Appendix (continued)

\begin{tabular}{llll}
\hline Name & Location & Role & Contribution \\
\hline L. Kappos & University Hospital & Author & $\begin{array}{l}\text { Designed and } \\
\text { Basel, University of } \\
\text { Basel, Switzerland }\end{array}$ \\
& & $\begin{array}{l}\text { conceptualized study, } \\
\text { reviewed the data, } \\
\text { drafted and revised the } \\
\text { manuscript content }\end{array}$
\end{tabular}

\begin{tabular}{llll}
\hline J.S. & McGovern Medical & Author & $\begin{array}{l}\text { Designed and } \\
\text { conceptualized study, } \\
\text { Solinsky } \\
\text { School, UTHealth, } \\
\text { Houston, Texas }\end{array}$ \\
& & $\begin{array}{l}\text { drafted and revised the } \\
\text { manuscript content }\end{array}$
\end{tabular}

\begin{tabular}{|c|c|c|c|}
\hline D.K.B. Li & $\begin{array}{l}\text { University of British } \\
\text { Columbia, } \\
\text { Vancouver, Canada }\end{array}$ & Author & $\begin{array}{l}\text { Reviewed the data, } \\
\text { drafted and revised the } \\
\text { manuscript content }\end{array}$ \\
\hline A. Bar-Or & $\begin{array}{l}\text { University of } \\
\text { Pennsylvania, } \\
\text { Philadelphia }\end{array}$ & Author & $\begin{array}{l}\text { Drafted and revised } \\
\text { the manuscript } \\
\text { content }\end{array}$ \\
\hline $\begin{array}{l}\text { H.-P. } \\
\text { Hartung }\end{array}$ & $\begin{array}{l}\text { Heinrich-Heine } \\
\text { University } \\
\text { Düsseldorf, Germany }\end{array}$ & Author & $\begin{array}{l}\text { Drafted and revised } \\
\text { the manuscript } \\
\text { content }\end{array}$ \\
\hline $\begin{array}{l}\text { S. } \\
\text { Belachew }\end{array}$ & $\begin{array}{l}\text { F. Hoffmann-La } \\
\text { Roche Ltd., Basel }\end{array}$ & Author & $\begin{array}{l}\text { Reviewed the data, } \\
\text { drafted and revised the } \\
\text { manuscript content }\end{array}$ \\
\hline A. Sauter & $\begin{array}{l}\text { F. Hoffmann-La } \\
\text { Roche Ltd., Basel }\end{array}$ & Author & $\begin{array}{l}\text { Analyzed the data, } \\
\text { drafted and revised the } \\
\text { manuscript content }\end{array}$ \\
\hline J. & $\begin{array}{l}\text { F. Hoffmann-La } \\
\text { Roche Ltd., Basel }\end{array}$ & Author & $\begin{array}{l}\text { Drafted and revised } \\
\text { the manuscript } \\
\text { content }\end{array}$ \\
\hline $\begin{array}{l}\text { H. } \\
\text { Koendgen }\end{array}$ & $\begin{array}{l}\text { F. Hoffmann-La } \\
\text { Roche Ltd., Basel }\end{array}$ & Author & $\begin{array}{l}\text { Reviewed the data, } \\
\text { drafted and revised the } \\
\text { manuscript content }\end{array}$ \\
\hline J. Han & $\begin{array}{l}\text { Genentech, Inc., } \\
\text { South San Francisco, } \\
\text { California }\end{array}$ & Author & $\begin{array}{l}\text { Analyzed the data, } \\
\text { drafted and revised the } \\
\text { manuscript content }\end{array}$ \\
\hline L. Julian & $\begin{array}{l}\text { Genentech, Inc., } \\
\text { South San Francisco, } \\
\text { California }\end{array}$ & Author & $\begin{array}{l}\text { Drafted and revised } \\
\text { the manuscript } \\
\text { content }\end{array}$ \\
\hline S.L. Hauser & $\begin{array}{l}\text { University of } \\
\text { California, San } \\
\text { Francisco }\end{array}$ & Author & $\begin{array}{l}\text { Designed and } \\
\text { conceptualized study, } \\
\text { reviewed the data, } \\
\text { drafted and revised the } \\
\text { manuscript content }\end{array}$ \\
\hline
\end{tabular}

\section{References}

1. Kappos L, O'Connor PW, Polman CH, et al. Clinical effects of natalizumab on multiple sclerosis appear early in treatment course. J Neurol 2013;260:1388-1395.

2. Kappos L, Radue EW, Chin P, Ritter S, Tomic D, Lublin F. Onset of clinical and MRI efficacy occurs early after fingolimod treatment initiation in relapsing multiple sclerosis. J Neurol 2016;263:354-360.

3. Kappos L, Giovannoni G, Gold R, et al. Time course of clinical and neuroradiological effects of delayed-release dimethyl fumarate in multiple sclerosis. Eur J Neurol 2015; 22:664-671.

4. Calabresi PA, Kieseier BC, Arnold DL, et al. Pegylated interferon beta-1a for relapsing-remitting multiple sclerosis (ADVANCE): a randomised, phase 3, doubleblind study. Lancet Neurol 2014;13:657-665.
5. Kappos L, Wiendl H, Selmaj K, et al. Daclizumab HYP versus interferon beta-1a in relapsing multiple sclerosis. N Engl J Med 2015;373:1418-1428.

6. Gold R, Giovannoni G, Selmaj K, et al. Daclizumab high-yield process in relapsingremitting multiple sclerosis (SELECT): a randomised, double-blind, placebocontrolled trial. Lancet 2013;381:2167-2175.

7. Cohen JA, Barkhof F, Comi G, et al. Oral fingolimod or intramuscular interferon for relapsing multiple sclerosis. N Engl J Med 2010;362:402-415.

8. Polman $\mathrm{CH}$, O'Connor PW, Havrdova E, et al. A randomized, placebo-controlled trial of natalizumab for relapsing multiple sclerosis. N Engl J Med 2006;354: 899-910.

9. Confavreux C, O'Connor P, Comi G, et al. Oral teriflunomide for patients with relapsing multiple sclerosis (TOWER): a randomised, double-blind, placebocontrolled, phase 3 trial. Lancet Neurol 2014;13:247-256.

10. Gold R, Kappos L, Arnold DL, et al. Placebo-controlled phase 3 study of oral BG-12 for relapsing multiple sclerosis. N Engl J Med 2012;367:1098-1107.

11. Fox RJ, Miller DH, Phillips JT, et al. Placebo-controlled phase 3 study of oral BG-12 or glatiramer in multiple sclerosis. N Engl J Med 2012;367:1087-1097.

12. Jacobs LD, Cookfair DL, Rudick RA, et al. Intramuscular interferon beta-1a for disease progression in relapsing multiple sclerosis: The Multiple Sclerosis Collaborative Research Group (MSCRG). Ann Neurol 1996;39:285-294.

13. IFNB Multiple Sclerosis Study Group. Interferon beta-lb is effective in relapsing remitting multiple sclerosis: I: clinical results of a multicenter, randomized, doubleblind, placebo-controlled trial: 1993 [classical article]. Neurology 2001;57(12 suppl 5):S3-S9.

14. PRISMS (Prevention of Relapses and Disability by Interferon beta-1a Subcutaneously in Multiple Sclerosis) Study Group. Randomised double-blind placebo-controlled study of interferon beta-1a in relapsing/remitting multiple sclerosis. Lancet 1998;352: 1498-1504.

15. Cohen JA, Coles AJ, Arnold DL, et al. Alemtuzumab versus interferon beta 1a as firstline treatment for patients with relapsing-remitting multiple sclerosis: a randomised controlled phase 3 trial. Lancet 2012;380:1819-1828.

16. Coles AJ, Twyman CL, Arnold DL, et al. Alemtuzumab for patients with relapsing multiple sclerosis after disease-modifying therapy: a randomised controlled phase 3 trial. Lancet 2012;380:1829-1839.

17. Johnson KP, Brooks BR, Cohen JA, et al. Copolymer 1 reduces relapse rate and improves disability in relapsing-remitting multiple sclerosis: results of a phase III multicenter, double-blind placebo-controlled trial: The Copolymer 1 Multiple Sclerosis Study Group. Neurology 1995;45:1268-1276.

18. Kappos L, Radue EW, O'Connor P, et al. A placebo-controlled trial of oral fingolimod in relapsing multiple sclerosis. N Engl J Med 2010;362:387-401.

19. Calabresi PA, Radue EW, Goodin D, et al. Safety and efficacy of fingolimod in patients with relapsing-remitting multiple sclerosis (FREEDOMS II): a double-blind, randomised, placebo-controlled, phase 3 trial. Lancet Neurol 2014;13:545-556.

20. Miller DH, Khan OA, Sheremata WA, et al. A controlled trial of natalizumab for relapsing multiple sclerosis. N Engl J Med 2003;348:15-23.

21. Kappos L, Gold R, Miller DH, et al. Efficacy and safety of oral fumarate in patients with relapsing-remitting multiple sclerosis: a multicentre, randomised, double-blind, placebo-controlled phase IIb study. Lancet 2008;372:1463-1472.

22. Kappos L, Gold R, Miller DH, et al. Effect of BG-12 on contrast-enhanced lesions in patients with relapsing-remitting multiple sclerosis: subgroup analyses from the phase 2b study. Mult Scler 2012;18:314-321.

23. Hauser SL, Bar-Or A, Comi G, et al. Ocrelizumab versus interferon beta-1a in relapsing multiple sclerosis. N Engl J Med 2017;376:221-234.

24. Kappos L, Li D, Calabresi PA, et al. Ocrelizumab in relapsing-remitting multiple sclerosis: a phase 2, randomised, placebo-controlled, multicentre trial. Lancet 2011 378:1779-1787.

25. Brown P. Tertiary pharmacology review: application number: 7610530 rig 1 s 000 2016. Available at: accessdata.fda.gov/drugsatfda docs/nda/2017/761053Orig1 s000PharmR.pdf. Accessed March 2, 2018.

26. Polman CH, Reingold SC, Edan G, et al. Diagnostic criteria for multiple sclerosis: 2005 revisions to the "McDonald criteria." Ann Neurol 2005;58:840-846.

27. Polman $\mathrm{CH}$, Reingold SC, Banwell B, et al. Diagnostic criteria for multiple sclerosis: 2010 revisions to the McDonald criteria. Ann Neurol 2011;69:292-302.

28. Rovira A, Auger C, Alonso J. Magnetic resonance monitoring of lesion evolution in multiple sclerosis. Ther Adv Neurol Disord 2013;6:298-310.

29. Genovese MC, Kaine JL, Lowenstein MB, et al. Ocrelizumab, a humanized anti-CD20 monoclonal antibody, in the treatment of patients with rheumatoid arthritis: a phase I/II randomized, blinded, placebo-controlled, dose-ranging study. Arthritis Rheum 2008;58:2652-2661.

30. Piccio L, Naismith RT, Trinkaus K, et al. Changes in B- and T-lymphocyte and chemokine levels with rituximab treatment in multiple sclerosis. Arch Neurol 2010; 67:707-714.

31. De Stefano N, Narayanan S, Francis GS, et al. Evidence of axonal damage in the early stages of multiple sclerosis and its relevance to disability. Arch Neurol 2001; $58: 65-70$. 


\section{Neurology}

Onset of clinical and MRI efficacy of ocrelizumab in relapsing multiple sclerosis

Frederik Barkhof, Ludwig Kappos, Jerry S. Wolinsky, et al.

Neurology 2019;93;e1778-e1786 Published Online before print September 4, 2019

DOI 10.1212/WNL.0000000000008189

This information is current as of September 4, 2019

Updated Information \&

Services

References

Citations

Subspecialty Collections

Permissions \& Licensing

Reprints including high resolution figures, can be found at: http://n.neurology.org/content/93/19/e1778.full

This article cites 30 articles, 1 of which you can access for free at: http://n.neurology.org/content/93/19/e1778.full\#ref-list-1

This article has been cited by 2 HighWire-hosted articles: http://n.neurology.org/content/93/19/e1778.full\#\#otherarticles

This article, along with others on similar topics, appears in the following collection(s):

All Clinical Neurology

http://n.neurology.org/cgi/collection/all_clinical_neurology

All Clinical trials

http://n.neurology.org/cgi/collection/all_clinical_trials

MRI

http://n.neurology.org/cgi/collection/mri

Multiple sclerosis

http://n.neurology.org/cgi/collection/multiple_sclerosis

Information about reproducing this article in parts (figures,tables) or in its entirety can be found online at:

http://www.neurology.org/about/about_the_journal\#permissions

Information about ordering reprints can be found online:

http://n.neurology.org/subscribers/advertise

Neurology ${ }^{\circledR}$ is the official journal of the American Academy of Neurology. Published continuously since 1951, it is now a weekly with 48 issues per year. Copyright Copyright (C) 2019 The Author(s). Published by Wolters Kluwer Health, Inc. on behalf of the American Academy of Neurology.. All rights reserved. Print ISSN: 0028-3878. Online ISSN: 1526-632X.

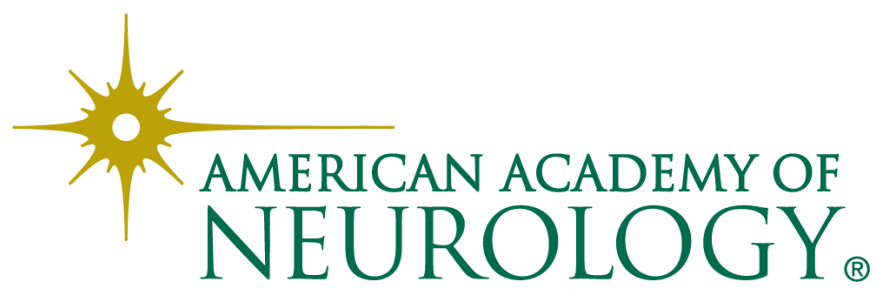

